\title{
Necrosis of the revascularized pulp in an immature infected maxillary second premolar following apexogenesis - a case report
}

\begin{abstract}
Nowadays, the trend in treating the infected immature permanent tooth is with disinfection and revuscularization of the root canal instead of apexification. By revuscularing the root canal and utilizing, a biocompatible material will create a new pulp tissue that can provide vital cells, which are able to continue the root formation to the normal length, wall thickness and close the apex. The purpose of this case report is to present a patient case where in revascularization of the infected immature tooth pulp space had been performed which end with necrosis after complete root formation. Iimmature maxillary permanent second premolar with a single canal revascularized in vivo by a blood clot from the periapical tissues into the canal space after disinfection. This case differ form other cases of revuscularization in that CMCP used as intracanal medicament in the first visit and the new pulp found non-vital after root completion.
\end{abstract}

Volume 9 Issue 6 - 2018

Bushra Rashid Noaman

Department of Pedodontics, Ishik University, Iraq

Correspondence: Bushra Rashid Noaman, Department of Pedodontics, Ishik University, Iraq, Tel 096475 I020748I, Email bushra.rashed@ishik.edu.iq

Received: November 23, 2018 | Published: December II, 2018

Keywords: immature tooth, revascularization, calcium hydroxide, apexogenesis, pulp necrosis

\section{Introduction}

Tooth viability can be maintained by the presence of vital pulp, because it supply the tooth with nutrition and biologically works as a sensor for pathogenic stimuli detection. The loss of vitality in an immature tooth leads to a poor crown-root ratio, thin walls of the root which is liable to fracture, and with an open apex. Every effort needed to attain the closure of foramen that remains open because of early pulp necrosis. This treatment could be by apexigenesis, which is a method of recharging the growth and restoring root growth and foramen closure, ${ }^{1}$ that is important for the long-term prognosis and integrity of the periapical tissues. The common treatment of an infected immature permanent tooth is by apexification using MTA or calcium hydroxid, which its disadvantages are the thin root walls and disproportion of crown-root length due to non- growth in the root but only a barrier closing the apical area of the root against guttapercha condensation, and the root will be weak and predisposed to fracture at any time. Nygaard-Ostby ${ }^{2}$ was the first in revascularizating the pulp space in necrotic, infected teeth, whose study was aimed to determine the reaction of the periodontal tissue if the whole pulp was removed from the canal and filled this empty canal with blood, the author stated that tissue formations could take place if the empty canal was filled only with blood from the periapical area, it has been noticed an increase in length of the root but the process stopped because of the shortage in materials and instruments. In most of cases of the non-vital teeth are infected, and the disinfection is the first phase of revascularization to ensure periapical healing. ${ }^{3-5}$ Iwaya $^{6}$ treated a necrotic, infected permanent tooth by revascularization after disinfection of infected root-canal dentine by topical use of a combination of ciprofloxacin, metronidazole and minocycline that used by Hoshino et al. ${ }^{7}$ and bacterial tight sealed of access cavity. Iwaya $^{6,8}$ used calcium hydroxide in the coronal part of the canal after disinfection and revascularization; the result was the disappearance of the radiolucency and the root increased in length and thickness after 5 months and complete root formation after 30 months occurred. Banchs \& Trope ${ }^{9}$ accomplished the same treatment but the MTA used instead of calcium hydroxide. Copious irrigation with $5.25 \%$ sodium hypochlorite, the radiolucency disappeared after 2 months and at the 24-months recall the root walls became thick and the growth of the root was analogous to the contiguous and contra lateral teeth. A case of non-vital infected immature mandibular second premolar was reported in which root formation took place after a single-visit calcium hydroxide apexification treatment. In this case, a barrier of hard tissue was formed, with a separate, mesioapically root growing, seven months after treatment. The auther concluded that changing of the calcium hydroxide is not always needed to induce apical closure. ${ }^{10} \mathrm{An}$ appropriate cleaning, shaping, asepsis, and filling of the root canal are the conditions must be available for the success of non-surgical root canal treatment ${ }^{11} \mathrm{An}$ effective regenerative endodontic method using a minor difference of the tri-antibiotic paste established by Hoshino and colleagues, as amoxicillin was used instead of minocycline, ${ }^{12}$ which results over an eighteen months period in healing of apical periodontitis and the draining sinus, the root became mature with the closure of the apex, and the tooth became responsive to pulp sensibility testing. Pulp revascularization is a process to induce blood inside the root canal to let vital cells inside the root from which specific cells can be formed. Those cells will form the root to the normal length and thickness and be more resistant to the forces of mastication than the tooth treated with apexification. ${ }^{12,13}$ The potent evidence for successful regenerative treatment is the following clinical outcomes; resolution of apical periodontitis, continued radiographic root development. ${ }^{14}$ The aim of this report is to present a case of infected immature permanent tooth treated with pulp revuscularization. Over instrumentation was the first step then Camphor phenol (CMCP) was used as canal disinfectant prior to the triple antibiotic followed by vital tissue formation in the apical half of the root. The vital cells in contact with calcium hydroxide, could form the root to the full length and thickness with closed apex. After complete root formation, the tooth lost its vitality. 


\section{Case report}

A nine years old boy referred to the pediatric clinic with normal medical history. The patient's chief complaint was pain on chewing in the upper left quadrant. Intraoral examination revealed the presence of a maxillary left second premolar with disto-occlusal temporary filling. The tooth was tender to percussion and redness in the gingival tissue beside the tooth was evident. The tooth treated by a dentist and the treatment was; access opening, instrumentation and dressed with camphorated monochlorophenol (CMCP) wetted cotton and temporary filling. The report of the dentist explained that over instrumentation done and injury of the periapical area happened. Periapical intraoral radiograph displayed that the tooth was immature with large periapical radiolucency (Figure 1). The child's economic status was poor and the MTA is expensive so the treatment performed by using calcium hydroxide. ${ }^{6,15}$

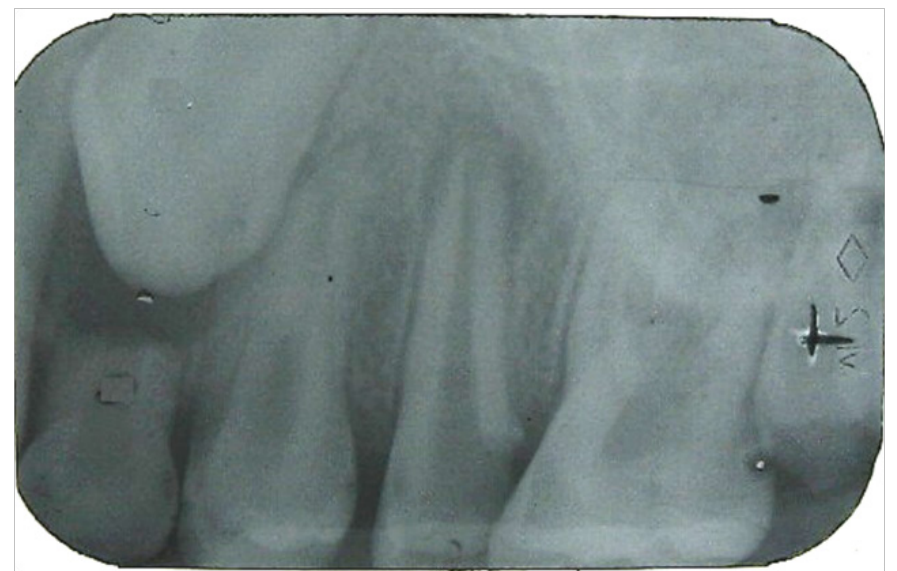

Figure I Diagnostic radiograph. The second premolar has open apex with a periapical radiolocency and disto-occlusal carious lesion extend to the pulp.

\section{Treatment procedure}

First visit: on removal of the temporary filling and $\mathrm{CMCP}$ cotton, there was bleeding in this time from the canal. The working length estimated which was $17 \mathrm{~mm}$ (without anesthesia and there was no pain). The pulp irrigated with $5.25 \%$ sodium hypochlorite then a triple antibiotic used inside the canal which was consisted of ciprofloxacin, metronidazol and minocycline $(100 \mu / \mathrm{ml}$ for each one mixed with distilled water as a paste before use). Care was taken in insertion of the antibiotic without touching the pulp chamber in order to avoid discoloration of the crown. Then the tooth dressed with a dry cotton palette and a temporary filling and appointment given after four weeks (Figure 1).

Second visit: All symptoms disappeared, the tooth re-entered, with consideration given in maintaining good isolation. On insertion of a paper point a resistant felt, and a pain felt by the patient nearly in the middle of the canal to this length the calcium hydroxide with barrium sulphate (Metapaste (Calcium Hydroxide w/ Barium Sulfate- Korea) injected in the coronal half of the root. The tooth restored and the $\mathrm{x}$-ray showed decrease in the size of the radiolocency after the use of the antibiotic paste in the canal for three weeks, and difference in the apical shape ( signs of healing), and the calcium hydroxide filled the coronal half of the canal in its first day of use (Figure 2).

\section{Follow up visits}

After six months: a healthy gingiva around the tooth was detected. The tooth examined the by percussion test, and by x-ray; there was no tenderness, and $\mathrm{x}$-ray revealed the decreasing size in the periapical radiolocency, and slight root elongation (Figure 3). The patient given an appointment after six months.

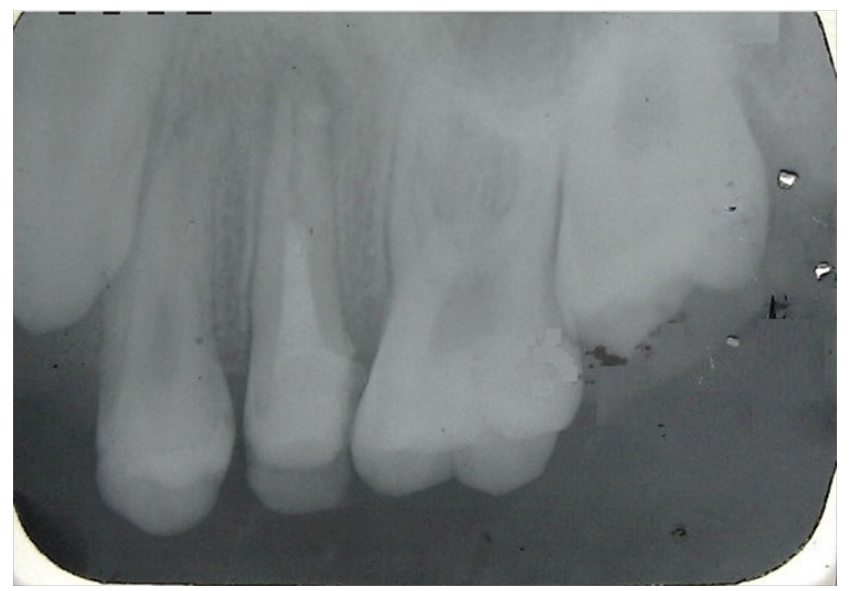

Figure 2 Radiograph after 28 days after the use of the triple antibiotic shows decrease in size of the periapical radiolocency and difference in the apical shape (signs of healing) from the first radiograph, and showing the calcium hydroxide to the half of the canal in its first day of use inside the canal.

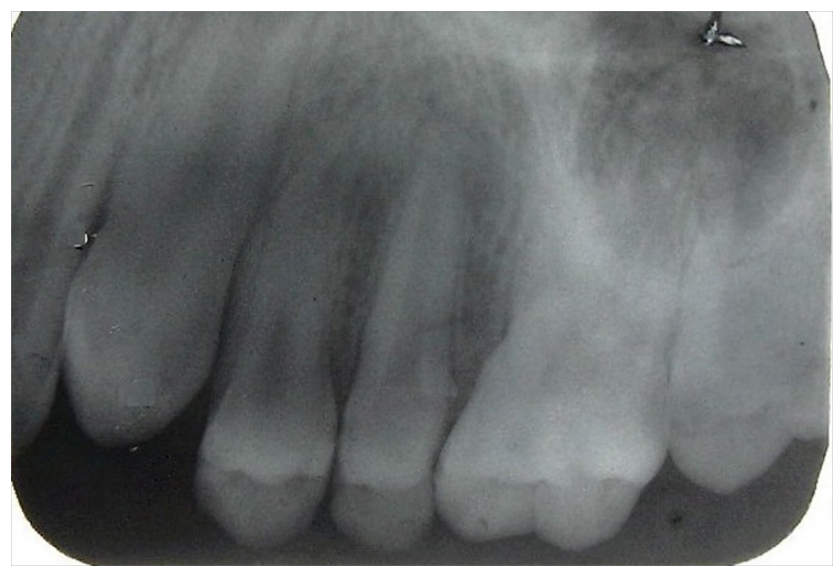

Figure $3 \mathrm{~A}$ radiograph 6 months after the use of calcium hydroxide showing noticable decrease size in periapical radiolucency, and slight root elongation.

Six months later: tooth was with no signs and symptoms. X-ray showed complete disappearance of the radiolocency, complete root formation, closure of the apex and increase in root walls thickness (Figure 4).

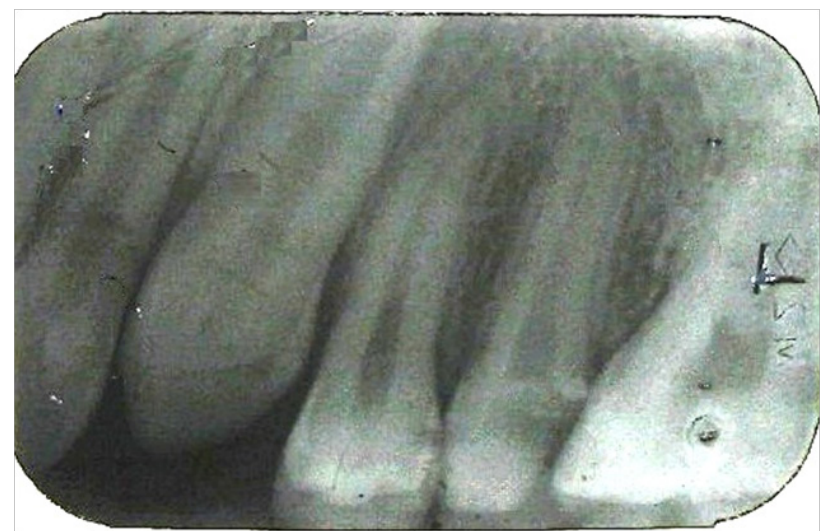

Figure 4 I 2 months after the use of the calcium hydroxide showing complete disappearance of the radiolocency and complete closure of the apex; increase in root length and thickness of the walls. 
Electric pulp testing was negative. The calcium hydroxide removed, a new working length estimated which was $21 \mathrm{~mm}$. Simple Instrumentation of the canal with a file at length $21 \mathrm{~mm}$, calcified tissue removed from the apical half of the canal. Rapid $2.5 \%$ sodium hypochlorite irregation with agitation and good dryness of the canal achieved, the canal filled with gutta percha by lateral condensation technique (Figure 5).

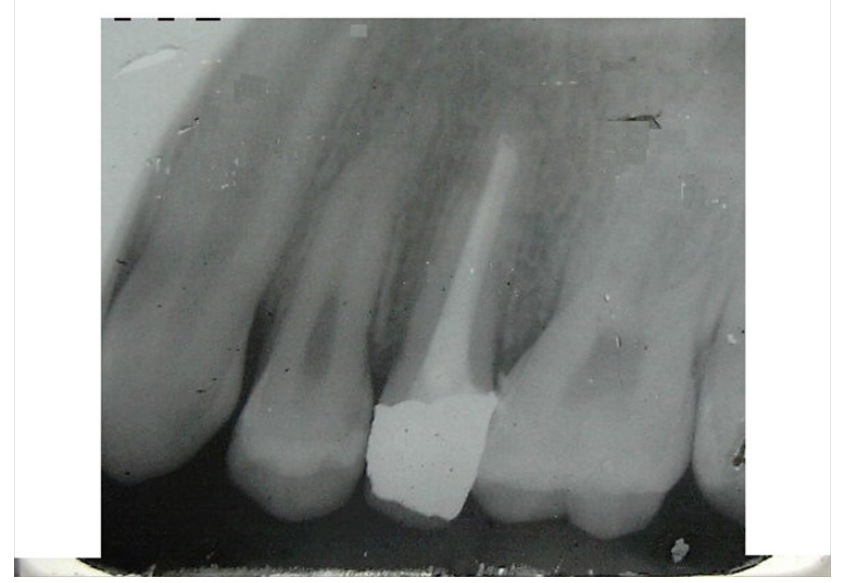

Figure $5 \mathrm{~A}$ radiograph 14 months after he use of the calcium hydroxide, showing the obturation with gutta percha on length $21 \mathrm{~mm}$.

\section{Discussion}

It is a chalenge to treat necrotic immature tooth due to trauma or caries endodontically, because of the open apex against gutta percha condensation and poor apical seal, thin root which can be fracture in the future and for the disproportion in the crown-root ratio. İn young patients the treatment of such a tooth should be with a long-term prognosis and must aim to maintain the integrity of the periapical tissues, those will put the dentist in a confront. In this case report early erupted maxillary second premolar before age of ten years gives the probability of long standing infection of the pre-successor which caused root resorption and early exfoliation, and bone resorption then early eruption of the permanent successor. The early infection in this permanent tooth may be related to long standing abscess can affect the amelogenesis of the permanent tooth bud lead to hypoplasia making the tooth liable for caries as soon as it erupts. Clinical case reports have showed that the possibility of treating immature infected permanent which are indicated for apexification may be treated by apexogenesis, ${ }^{2,6,8}$ The process that happen in pulp revascularization of the necrotic immature tooth is resumbling in action to reimplantation of the an avulsed immature tooth; an open apex and a short root that permits new tissue to grow agin inside the pulp space readily, in which the canal is not infected therefore, it can work as a scaffold for growing of new tissue. After avulsion of the immature permanent tooth, the apical part of the pulp may remain vital then after re-implantation this vital pulp will proliferate coronally replacing the necrotized portion of the pulp. In this case there was an injury of the periapical tissue during pulp extirpation by the first dentist, the blood transferred inside the root canal and acted as a scaffold for new vital cells to form, which could reform the root as in many research studies. ${ }^{6,8,16}$ While the protocol of pulp revuscularization ${ }^{17}$ didn't state the use of CMCP, which is used sometimes as root canal antiseptic ${ }^{18}$ and it is used in this case prior to the start with the first step of the protocol. The root canal debridement is necessary to provide a suitable environment for the regeneration to take place, therefore the root canal irrigated by $5.25 \%$ sodium hypochlorite instead of instrumentation to avoid further weakness of the root. ${ }^{19}$ The use of the tripple antibiotic ${ }^{7}$ would decrease the number of microorganisms then healing of the periapical infection could takeplace, and from the x-ray (Figure 2) appears that the size of the lesion decreased and the root started increasing in length, which indicates the sterilization of the canal is the first treatment that should be done. İn the presence of the blood which induced from the periapical area by over instrumentation done by the first dentist and completion of the sterelization, tissue formed inside he canal which contain the vital cells that started apexogenesis after utilizing the calcium hydroxide in contact with this tissue. In the traditional methods of pulp revascularization, the material used is the MTA but in this case the calcium hydroxide used since it is biocompatable and used in direct pulp capping and pulpotomy of immature permanent teeth in contact with the pulp and the same material used by many researchers, ${ }^{6,18}$ and its notable healing of periapical infection and hard tissue barrier formation. ${ }^{6,8,20}$ The effect of calcium hydroxide inducing periapical healing could be referred to both its antibacterial and mineralizing effects, the high alkalinity (usually $\mathrm{pH} 12$ to 13 ) of the calcium hydroxide can distroy the microorganisms when put in direct contact with them. After the distruction of the bacteria, their substrate will be neutralized. When the calcium hydroxide put in contact with vital connective tissue in the root canal had the same effect as when it is used as a direct pulp capping material, therefore, success of root canal therapy is increased. İ this case large peripical lesion healed completely within a period of 12 months by the use of calcium hydroxide as an intracanal medicament. Before the obturation of the canal with gutta perch the canal irregated with rapid $2.5 \% \mathrm{NaOCl}$ to insure complete removal of the calcium hydroxide to minimize softening of dentine and maintain unaltered canal shapes. Agitation was used with the irregation to insure the maximum removal of calcium hydroxide. ${ }^{21}$ The stage of root in the current case is stage 8 according to Mendoza et al. ${ }^{22}$ study in 2010 in which one third of the root was formed before necrosis of the pulp. The periapical repair was with round apex due to continued root formation until normal appearance of the root obtained which is considered a cementoid type closure according to Mendoza et al. ${ }^{21}$ In spite that the tooth became necrotic but before its necrosis the crown tooth ratio corrected, the walls become thicker and the apex closed so it was successful in comparison with apexification technique.

\section{Conclusion}

This tratment approach could heal the periapical infection and promoted root development. This case is differ in treatment from the protocol of the revuscularization, that CMCP used in the first visit. This treatment approach could help in saving infected immature tooth by physiologically reinforcing the root walls and increase the root length. In this patient, the 12-months recall clinical and radiographic examination was consistent with an immature tooth that had successfully re-vascularized but ended with pulp necrosis. The result of this case suggests the necessity of follow-up of those cases to test the vitality.

\section{Acknowledgments}

This research supported by research centre of Ishik University, Erbil, Iraq.

\section{Conflicts of interest}

The author declares that there is no conflicts of interest. 


\section{References}

1. Anantharaj A, Praveen P,Venkataraghavan K, et al. Challenges in pulpal treatment of young permanent teeth a review. J Dent Scien Res. 2011;2:142.

2. Ostby BN. The role of the blood clot in endodontic therapy: an experimental histologic study. Acta Odontol Scand. 1961;19:324-353.

3. Binnie,William H, Rowe A. Ahistological study of the periapicaltissues of incompletely formed pulpless teeth filled with calcium hydroxide Journal of Dental Research. 1973;52(5):1110.

4. Bergenholtz G. Micro-organisms from necrotic pulps of traumatized teeth. Odontol Revy. 1974;25(4):347-358.

5. Shuping G, Ørstavik D, Sigurdsson A, et al. Reduction ofintra canal bacteria using Nickel-titanium rotary instrumentation and various medications. J Endod. 2000;26(12):751-755.

6. Iwaya S, Ikawa M, Kubota M. Revascularization of an immature permanent tooth with apical periodontitis and sinus tract. Dent Traumatol. 2001;17(4):185-187.

7. Sato I, Kurihara-Ando N, Kota K, et al. Sterilization of infected rootcanal dentine by topical application of a mixture of ciprofloxacin, metronidazole and minocyclin in situ. International Endodontic Journal. 1996;29:118-124.

8. Iwaya S, Ikawa M, Kubota M. Revascularizationofan immature permanent tooth with periradicular abscess after luxation (casereport). Dent Traumatol. 2011;27:55-58.

9. Banchs F, Trope M. Revascularization of immature permanent teeth with apical periodontitis: new treatment protocol. J Endod. 2004; 30(4):196200.

10. Gupta S, Sharma A, Dang N. Apical bridging in association with regular root formation following single-visit apexification: A case report. Quintessence Int.1999;30(8):560-562.

11. Taneja S, Kumari M, Prakash H. Non-surgical healing of large periradicular lesions using a triple antibiotic paste: A case series. Contemporary Clinical Dentistry. 2010;1(1):31-35
12. Thomson A, kahler B. Regenerative endodontics-biologically- based treatment for immature permanent teeth: acase report and review of the literature. Aust Dent J. 2010;55(4):446-452.

13. Archana S,Varri S, Bolla N, et al. Revascularization- an overview. Journal of international dental and medical research. 2012;5(1):55-59.

14. Kenneth M, Anibal D, Fabricio B. Treatment options: basis of regenerative endodontic procedures. J Endod. 2013;39(3 Suppl):S30-S43.

15. Deepti A, Shifa S, Muthu M, et al. Apical closure of immature molar roots: A rare casereport. Int J Clin Pediatr Dent. 2008;1(1):54-57.

16. Trope M. Treatment of the immature tooth with a non-vital pulp and apical periodontitis. Endodontic topics. 2006;14(1):51-59.

17. Mandwe Ashish P, Patil Pravin G, Shetty Heeresh K, et al. Role of triple antibiotic paste in revascularization and endodontics - a review. International Journal of Contemporary Medical Research. 2015;2(2):186-190.

18. Neelkantan P, Rajendran S. Application of antiseptic in endodontics. Int J Pharm Sci Res. 2013;22(2):232-234.

19. Sheehy E, Roberts G. Use of calcium hydroxide for apical barrier formation and healing in nonvital immature permanent teeth; areview. $\mathrm{Br}$ Dent J. 1997;183(7):241-246.

20. Leonardo M, SilvaL A, Leonardo Rde T, et al. Histological evaluation of therapy using a calcium hydroxide dressing for teeth with incompletely formed apices and periapical lesions. JOE. 1993;19(7):348-352.

21. Huda Y, Ahmed J, Yan Y, et al. Quantitative Comparison of Calcium Hydroxide Removal by Endo Activator, Ultrasonic and ProTaper File Agitation Techniques: An in vitro Study. J Huazhong Univ Sci Technolog Med Sci. 2013;33(1):142-145.

22. Mendoza MA, Reina E, Garıca-Goday F. Evaluatıon ofapical formation on immature necrotic permanent teeth. American Journal of Dentistry. 2010;23(5):269-274. 